\title{
Ensaio sobre "Ser dispositivo ou ser agenciamento" - Uma coleção de Nike, dramaturgia, política e outros itens
}

Test on "Being device or agency" - A collection of Nike, dramaturgy, politics and other items

Eduardo de Almeida Santos ${ }^{1}$ 


\section{Resumo}

O presente artigo trata sobre questões de agenciamento e vivência. Tanto em trabalhos reconhecidos como a encenação de Esperando Godot, de Suzan Sontag, como a criação dramatúrgica de: Oh! Menino, de um grupo de teatro de comunidade. Destas relações pretende-se perceber a dinâmica de jogo e disputa em campos como política, subjetividades e artes principalmente em zonas de conflitos.

Palavras-chave: Agenciamento; zonas de conflito; representação teatral

\section{Abstract}

The present work deals with issues of agency work both recognized as the staging of Waiting for Godot, by Suzan Sontag, as dramaturgical creation of a community group called: Oh! Menino. These relationships are intended to capture the dynamic of the play and compete in such fields as politics, subjectivities and arts especially in conflict zones.

ISSN: 1414.5731

E-ISSN: 2358.6958

Professor, diretor e dramaturgista. Mestre em Ciência da Literatura pela UFRJ. eduardoteffé@gmail.com 
O que eu fiz? Usei o mesmo método que os atraiu para o tráfico para retirá-los. Viajava para Nova York, comprava os melhores tênis, casacos, e andava na favela. Todos se viravam, numa coreografia de cotovelo e pescoço, para me admirar. Tinha que trabalhar com ostentação. (José Junior - AfroReggae, 2013)

Estive recentemente em uma reunião de um grupo político/movimento de "esquerda". O grupo que estava rediscutindo a sua "identidade" possuía alguns de seus membros em partidos políticos (sendo alguns eleitos vereadores e deputados) e outros membros em movimentos sociais, sobretudo, relacionados a trabalho e à terra. O "grande problema" deles, que os forçava a rediscutir seu programa e ações, era: as políticas sociais implementadas pelos Governos de Fernando Henrique Cardoso (1995-2002) e ampliadas nos Governos Lula-Dilma (2002-2016) que eclipsavam a percepção da luta de classes.

Este "eclipse da política" é um dos grandes problemas para os "agentes da política" da contemporaneidade. Refiro-me assim a agentes, porque acredito que este problema de a política estar eclipsada atinge tanto os políticos tradicionais e os movimentos sociais, quanto também atinge os atuantes da política que agem em micropolíticas ou em outras formas. Deste último tipo de agir cabe notar, por exemplo, os grupos e atuantes teatrais que optam por fazer um teatro mais "engajado" e/ou "político".

Segundo Cocco (2009), as questões das políticas sociais, as penetrações tecnológicas e midiáticas e as consequências das relações entre distribuição de renda e crescimento econômico acabaram por misturar as tradicionais clivagens teóricas, políticas e suas práticas. Inseridos nesses cenários ficou difícil enxergar com nitidez as categorias e os pares teóricos de oposição convencionais e sólidos (como o subalterno/hegemônico, o tradicional/moderno e o trabalhador/capital).

Talvez as lutas de classes continuem a existir, mas as mesmas se encontram muito mais turvas em decorrência de suas novas modalidades de organização cultural, de novas dinâmicas de consumo e da hibridação das tradições de classe. É cada vez mais notório que as sociedades estão se deslocando de uma localização da "arquitetura que era possível definir" para o "território do gás e do vazado"2. É este deslocar para o lugar do "território do gás e do vazado" que dessincronizou as aplicabilidades das teorias da "arquitetura sólida". Mudar de lugar deveria ter como processo natural o abandonar das velhas operações e dos velhos instrumentos conceituais. Mas abandonar algo e criar algo novo não é tão fácil assim.

Primeiro ponto é que formar novos conceitos e novos léxicos não anulam por completo os conceitos e léxicos antigos. Por trás de palavras, comportamentos e conceitos existem todo um caminho e um processo. Uma nova palavra não apaga de imediato as relações de uma antiga palavra. Talvez a esta noção esteja mais próxima a questão do "Cânone" e sua disputa: uma nova obra que entre no cânone necessariamente não retira uma outra. E mesmo quando esta é retirada, não se apagam

${ }^{4}$ É notório esse pensamento nas obras que tratam a liquidez em Bauman, ou a fragmentação do individuo em Hall, ou mesmo sobre o espaço urbano em Cancline e Anderson. 
a percepção e as relações criadas por ela na memória de alguns. Não se desaparece simplesmente. As palavras e conceitos têm em si ação e memória. As palavras e conceitos poderiam ser análogas (ou estarem incluídas) no que Bourdieu chama de habitus. "Sendo produto da história, o habitus é um sistema de disposições aberto, permanentemente afrontado a experiências novas e permanentemente afetado por elas. Ele é durável, mas não imutável" (Bourdieu, 2002, p. 83).

O segundo ponto é que alguns termos lidos como "inexistências" (como a "inexistência de classes") não são em si inexistentes, estão apenas mais turvos nas suas possibilidades de visualização. Assim, se por um lado, o confronto entre capital e trabalho não esteja sendo compreendido como campo integralmente em disputa e as disputas e oposições convencionais não sejam mais possíveis de serem percebidas da forma clássica. Por outro lado, o Capitalismo atual continua produzindo processos de exclusão - mesmo nos casos em que incluem. É esta relação dialética que provoca este eclipse político ou torna a sua visualização turva. As relações de dominação não colocam em lados opostos do campo os seus "jogadores", mas misturam os mesmos, sem, no entanto, retirarem a "vantagem" de alguns. As ferramentas de dominação passaram a operar não mais com o objetivo de excluir diretamente, mas sim com o de incluir com matrizes geradoras de exclusão (que necessariamente não são percebidas).

O que foi percebido é que colocar em lados opostos poderia causar revolta e estados de reivindicação. Assim colocaram no mesmo lado os agentes desiguais, sem tirar suas desigualdades. Exemplificando, quem gere o Capital percebeu que excluir alguém era perder uma possibilidade de mercado, portanto, tornou-se um mecanismo para ampliar sua inclusão econômica, mas esta não restringiu o seu mecanismo implícito, o processo de "dessubjetivação". Ou ainda, as populações periféricas do Rio de Janeiro têm ao seu alcance bens desejáveis do consumo moderno (como celulares e televisões compradas a prazo), mas não conseguem ter o pleno direito a uma saúde de qualidade (vide a crise da saúde pública na maior parte do Brasil).

É sintomático disto o processo de apropriação de ícones da contracultura ou da ideologia da "esquerda" pelo mercado. Assim é comum ver a iconoclastia do Che Guevara (1928-1967) apropriada pela indústria da moda. De certa forma, "capitalizaram o Che". Outro ponto assimilado é o "Tênis All Star", que foi ícone contra o sistema comercial e da revolta da juventude. Hoje, a empresa produtora de tal tênis tem como acionista majoritário, a Nike ${ }^{3}$, possivelmente a maior representante do sistema mainstrem da cultura da moda em relação a tênis e material esportivo. Assim, mesmo fugindo do "Capitalismo" ou da "dominação", pertence-se aos mesmos. Mesmo sendo contra, se é incorporado a isso.

Mas a vida é potência e resiste como afirmação. E os caminhos podem ser percorridos em direções inversas. Pode-se usar as estratégias de dominação como ferramentas de libertação. A "verdade" é que as estratégias são só estratégias. Dominação ou libertação dependem do seu uso e do contexto. Deleuze (2001), por exemplo, dizia que é a repressão que determina a diferença entre os dispositivos (de controle) para os agenciamentos de desejo. A arte pode realizar o elo entre articulação e a vi-

${ }^{3}$ In: http://www1.folha.uol.com.br/folha/dinheiro/ult91u70092.shtml 
vência dessas comunidades com a produção de material estético - através do dialogo de artistas-comunidade-público. De certa forma, é o que nos diz Ranciére em seu livro A partilha do sensível: ${ }^{4}$

A conexão dessas "simples práticas" com modos de discurso, formas de vida, ideias do pensamento e figuras da comunidade não é fruto de nenhum desvio maléfico. Em compensação, o esforço para pensá-la implica abandonar a pobre dramaturgia do fim e do retorno, que não cessa de ocupar o terreno da arte, da política e de todo objeto pensado. (Rancière, 2005, p.14)

\section{Sobre teatro e política ou entre dominação e agenciamento}

Vamos nos deter sobre a questão do teatro e da política para voltarmos a isso: as percepções de estratégias de dominação ou agenciamento. Façamos algumas analogias e desenvolvamos um pouco mais sobre isso, tendo dois exemplos como norte: a encenação de Esperando Godot descrita por Susan Sontag no seu ensaio Esperando Godot em Saravejo, e pelas observações colhidas por mim em relação ao coletivo Última Estação, da favela da João XXIII no estado do Rio de Janeiro. São dois exemplos que estão situados fora do mecanismo do Teatro Privatizado (e depois "privado") e que servem para discutir estas questões.

Sontag (2005) escreve o seu ensaio sobre a experiência de ser convidada para encenar algo (e encenar) na temporalidade do cerco a Saravejo, o cerco mais longo da história da guerra moderna ${ }^{5}$. A peça escolhida foi Esperando Godot. A sensação que ela descreve em seu ensaio é que para alguns, Esperando Godot poderia ser, ao mesmo tempo, uma obra perfeitamente adequada ou não à esta situação. Consideravam adequada pela "semelhança" de contexto da época de encenação (o cerco) e da produção da obra ( $2 \circ$ Guerra Mundial). E para outros seria inadequada porque seria melhor nesta "realidade do cerco, terror e guerra" montar uma comédia ou um vaudeville para distrair as pessoas. Logo, seria possível pensar tanto que a peça de Samuel Beckett parecia ter sido escrita para Sarajevo e sobre Sarajevo, como poderia se perguntar sobre quem iria assistir a uma apresentação de Esperando Godot em Saravejo naquelas condições.

O primeiro destes pensamentos poderia ser complementado com a possibilidade que uma boa obra tem de parecer ser feita para determinados contextos, sejam estes do "mundo concreto" como o da "realidade do imaginário e subjetividade". Assim, Esperando Godot pode penetrar profundamente tanto em uma realidade de guerra concreta como em um conflito do indivíduo contemporâneo que não perce-

\footnotetext{
${ }^{4}$ Jacques Rancière (Argélia, 1940) é um filósofo francês, professor da European Graduate School de Saas-Fee, e professor emérito da Universidade de Paris. ${ }^{5}$ O Cerco a Saravejo foi realizado pelas forças sérvias da autoproclamada "República Srpska" e do Exército Popular lugoslavo. Durou de 5 de abril de 1992 a 29 de fevereiro de 1996, durante a Guerra da Bósnia, entre as mal equipadas forças de defesa da Bósnia e Herzegovina, o Exército Popular lugoslavo e o Exército da "República Srpska", situados nas colinas que rodeiam a cidade. Após a Bósnia e Herzegovina escreverem a sua declaração de independência da República Socialista Federativa da lugoslávia, os sérvios, cujo objetivo estratégico era criar um novo Estado sérvio da "República Srpska" que incluiria parte do território da Bósnia e Herzegovina, cercaram Sarajevo com uma força de cerca de 18.000 homens. Baseados nas colinas circundantes, assaltaram a cidade com armamento pesado, que incluía artilharia, morteiros, tanques, canhões antiaéreos, metralhadoras pesadas, lançadores múltiplos de foguetes, mísseis lançados de aeronaves e rifles sniper. Em 2 de maio de 1992, os sérvios bloquearam a cidade. As forças de defesa do governo bósnio, que estavam muito mal equipadas, foram incapazes de romper o cerco. E os residentes ficavam na expectativa de uma intervenção internacional (capitaneada pelos EUA - intervenção esta que "demorou muito a acontecer"). Estima-se que mais de 12.000 pessoas foram mortas e 50.000 feridas durante o cerco, sendo $85 \%$ das vítimas civis. Por causa destas mortes e da migração "forçada", em 1995, a população da cidade caiu para 334.663 pessoas (64\% da população de antes da guerra). (In: https://veja.abril.com.br/mundo/ 1992-1995-quatro-anos-de-guerra-na-bosnia/. Acesso em: 10 maio 2016).
} 
be o porquê de sua existência na vida de classe média, em uma "cidade perfeitamente normal". Já a pergunta sobre os espectadores é respondida pela própria Sontag em seu ensaio, quando diz que provavelmente seriam as mesmas pessoas que iriam assistir Esperando Godot, caso não houvesse um estado de sítio.

O gesto político operado por Sontag é o de agenciar a vivência como potência e estender a realização teatral como vetor de manifestação de subjetividades. $O$ que esta ação promove é para o público a de revigorar, consolar e a possibilidade de transcender para alguns (quando o seu sentido de realidade é ressignificado e "transportado"). Para os profissionais de teatro, isto ganha uma potência ainda maior, porque encenar nestes contextos lhes permitia serem normais e realizarem o seu cotidiano antes da Guerra (e não se aterem apenas às atividades do estado de sítio como carregadores de água ou receptores passivos de ajuda humanitária - passividade frente ao cerco). Estes fatos são apontados por Sontag em seu ensaio, mesmo ela considerando a contradição de que seria muito mais útil como "médica ou engenheira hidráulica"

É claro que existia o risco iminente de morte em se encenar em um território com tal conflito. A própria Sontag admite isso. Para ela, tanto os atores como espectadores poderiam "ser assassinados ou mutilados por tiros de um franco-atirador ou pelo obus de um morteiro, na ida ou na volta do teatro" (2004, p.384), mas isto não era um risco só deles, o mesmo poderia ocorrer nas suas próprias casas ou nas ruas em atividades necessárias. Privar-se do prazer teatral não significava um estado de segurança, apenas a manutenção deste estágio onde o biopoder retirava "as manifestações de subjetividade e resistência".

O raciocínio exposto acima lembra-me de um fato que eu presenciei em uma aula de teatro ministrada por Alexandre Damascena ${ }^{6}$ no projeto ELT (Escola Livre de Teatro na Cidade) das Crianças em Santa Cruz (RJ). Na ELT eram oferecidas oficinas de formação e capacitação artísticas em um bairro (Santa Cruz) periférico e carente de equipamento culturais da cidade do Rio de Janeiro. Em uma das aulas em que o professor Alexandre Damascena emitia alguns comandos improvisacionais de ação e lugar, como "curtindo na praia", " o carnaval para você", ele emitiu o comando "tiroteio onde você mora". Mediante a isto, uma parte da turma abaixou-se, a outra tentou esconder-se e um garoto (Tony) caminhou normalmente. Após esta ação e com o jogo teatral em pausa, uma boa parte das pessoas dirigiu-se a ele e perguntou: "Tony, era um tiroteio, você ouviu né"? Ele respondeu de imediato: "Claro que eu ouvi, mas tem tiroteio vira e mexe no meu bairro. Se eu for me esconder, gritar, fugir toda vez, eu não vou viver". Este gesto pode ser lido como metáfora tanto para Saravejo como para nossas vidas. A guerra ou os dispositivos de controle estão sempre cerceando as pessoas, se elas deixaram de agir por este temor, terão sua potência de vida roubada.

Mas voltemos a Sontag, para depois retornarmos ao "teatro de comunidade". 0 fazer teatro é uma destas possibilidades de ser potência em vida. E o teatro era um vetor libertário em um contexto em que a guerra era um misto de desapontamento, dispositivo de cerceamento da vida e espetáculo de mídia (no ensaio de Sontag existe

${ }^{6}$ Alexandre Damascena é professor da rede pública de Itaguaí e doutorando em Literatura pela UFRJ, ator e diretor de Teatro de diversas companhias de teatro da Zona Oeste do Rio. 
a menção a um diálogo dela com o dono do hotel onde a mesma estava hospedada. No ensaio, Sontag, diz que o dono do hotel comentou surpreendido que não tinha uma lotação tão alta e com tantos jornalistas desde a Olimpíada de Inverno).

É importante perceber que o teatro como gesto político ou agenciamento vai além da mera reprodução de fatos ou da simples identificação, como a que poderia ocorrer no contexto de Saravejo à espera da intervenção do presidente norte-americano (Bill Clinton) e a chegada do mensageiro para dizer que os "personagens/eles" esperaram em vão. Este teatro é capaz de articular a vivência de forma a encantá-la e a vetorizá-la. Vai além da mera psicologia, ou da mera reprodução de fatos ou ainda da "ideia". Ele é potência onde alguns percebem carência.

Agora cabe notar que toda esta potência tem limites: a peça Esperando Godot não tinha a capacidade de parar a guerra no mundo concreto. Sontag também admite que sua ajuda em fazer teatro não seria superior à de outras áreas (apenas era aquilo que ela podia fazer) e que talvez a maior mudança fosse nela mesma. E fundamentalmente, fez-se teatro PARA e COM Saravejo. Dito isto, voltemos a trabalhar a questão do "teatro comunidade" e suas possibilidades de se tornar agenciamento ou dispositivo.

\section{A Favela enquanto (re)existência}

A periferia/favela/comunidade da cidade do Rio de Janeiro sempre foi constantemente "descoberta" e "representada" ao longo dos séculos XX e XXI. "Descobriram" e a "representaram" nestes períodos os modernistas brasileiros, a igreja católica, a literatura, os piscors ${ }^{7}$ as ONGs, os agentes públicos, os agentes políticos, dentre outros. Mas estas descobertas e representações nem sempre foram agenciamentos e incluíam as subjetividades. Muitas vezes foram dispositivos de "aprisionamento" e controle. Nem sempre foram os próprios sujeitos a portarem suas vozes e muitas vezes o que viria para "facilitar" ou "ajudar" se tornava uma espécie de "colonização".

É desses rastros que surgem, por exemplo, a "dramaturgia puramente social". Esta escrita dramática é muitas vezes apresentada como a narrativa do exótico ou do overside da sociedade, em que se apresenta uma tela de excluídos, dos não assistidos ou dos que não pertencem à sociedade-cidade. Cabe ressaltar, no território perigoso da ausência de estatísticas, que a maioria destas dramaturgias ditas sociais hoje são produzidas por dramaturgos de fora da comunidade, muitas vezes, escritas em seus apartamentos confortáveis longe do convívio ordinário com estes territórios. Aliás, estes quando fazem uso da ideia de dramaturgia social se utilizam disto como uma espécie de o capital social para venda da ideia da mitologia dos "excluídos" ou dos exóticos.

Outro miscigenação e resultado de representação possível é a favela/ comunidade folclórica onde todos os problemas são superados por pessoas mulatas e negras que são criativas e estão sempre dançando, criando e superando todas as dificuldades. Registradas em um tempo da rememoração de um passado/presente nostálgico sempre no campo da poesia e da fantasia.

${ }^{7}$ Uma forma de voluntariado. 
A tentação de ser bom também entra neste jogo e tenta-se ensinar para a "comunidade" como fazer teatro ${ }^{8}$, como ser bom, como ser um ser humano pleno realizado entre outros ensinamentos. Mas tudo isto sempre pela ótica do enunciador e no erro de considerarem sempre pelas carências e ignorarem os processos de subjetividades gerados pelas ausências (isto quando as mesmas realmente existem).

Outro ponto que poderíamos colocar como adendo a esta questão é o surgimento da população de favela e comunidade tanto como produto como potencial mercado consumidor que estão ganhando cada dia mais destaque por parte da mídia e do sistema econômico no Brasil. Como produto, porque a favela ganhou o status de produto tipo exportação e de interesse imagético. Como mercado pelos motivos de quantitativo habitacional e econômicos (a classe C e D são as grandes classes consumidoras do Brasil hoje ${ }^{9}$ )

A intelectualidade e os sistemas de representação não poderiam ignorar isso ${ }^{10}$. Estes territórios direta ou indiretamente pertencem e são capazes de interferir na história, logo, não faz mais sentido ignorar "a fala destas bocas" no sentido do curso. Também não faz mais sentido tentar representar um mundo a que estas pessoas não pertencem. Estes territórios renovados e transformados em uma subcultura potencial têm a necessidade de um linguajar para se entenderem e de uma imagem para se reconhecerem. Portanto, cabe aqui notar a metodologia do incluir para excluir.

É importante lembrar que as palavras favelas e comunidade têm múltiplas conotações e possibilidades dentro de suas fronteiras geográficas, identitárias e culturais e estão se definindo e a definir em um processo constante. E todos estes processos de "descobertas" não se sobrepõem, mas vão se juntando, tencionando e dialogando de forma direta ou não. A palavra "favelado", por exemplo, vai do adjetivo pejorativo para exprimir um preconceito étnico-social até um substantivo de identidade folclórica de felicidade e modo de vida (razão pelo qual muitos dos habitantes destes territórios preferem a palavra "favela" à palavra "comunidade").

Fato é que existem modelos positivos e não apenas modelos negativos e, enquanto as representações por vezes operam nos extremos, a "realidade" não opera em nenhum deles, mas no entre. Os seus graves problemas sociais estão em jogo ao mesmo tempo que suas imaginações e criatividades. Nunca é um ou outro, mas sempre o seu jogo ou a disputa de seu território. Os seus processos sociais são mutantes (como em todas as comunidades são).

As dinâmicas de representação e alguns dispositivos de subjetividade, que deveriam ser agenciamento, muitas vezes não percebem isto ou não são usados para tal. É comum ver ONGs que trabalham com teatro continuarem reproduzindo pensamentos para pessoas com poucas competências, desejos e subjetividades. Facilitadores que, querendo libertar, acabam por colonizar. É neste sentido que eu acredito em

\footnotetext{
${ }^{8}$ Esse tipo de teatro que foi, por exemplo, praticado em ONGs como o Galpão Aplauso não se sustenta quando há a ausência de patrocínio ao contrario de iniciativas feitas para e com a comunidade como o Grupo "Nós do Morro" ou a "Cia Marginal".

9 Segundo a Revista Exame em 2016, as periferias brasileiras movimentaram mais de 141 bilhões de reais. Só as classes B2, C1 e C2 responderam por 96 bilhões de reais desse montante. In: https://exame.abril.com.br/marketing/potencial-consumo-maiores-comunidades-favelas-brasil/. Acesso em: 6 set. 2017. 10 No campo da vivência pessoal, cabe ressaltar que tive um trânsito artístico muito próximo desse dito "tipo de teatro": quando partilhei formações artísticas no Teatro da Cidade das Crianças, em que membros de grupos oriundos de Santa Cruz, Campo Grande, Paciência (bairros periféricos da cidade do Rio de Janeiro) e Itaguaí (município vizinho da mesma cidade) se encontraram na Escola Livre de Teatro (ELT), a fim de buscar ferramentas práticas artísticas e relações societais. O próprio grupo MGT Os Coloridos (situado na cidade de Itaguai), onde iniciei minhas atividades teatrais, tinha certos traços do denominado "teatro de comunidade",
} 
fenômenos culturais, artísticos, sociais e políticos quando realizados por membros destes próprios territórios ou, no mínimo, por pessoas que entendam que o teatro que se faz PARA e COM os mesmos tem muito mais potência.

\section{O caso de: Oh! Menino - uma peça de memórias e sonhos de um coletivo da favela do João XXIII}

Para entrarmos no território da análise concreta pensemos um pouco sobre o texto dramático e a temporada de Oh! Menino realizado pelo coletivo Última Estação. Este grupo tem este nome porque o mesmo se localiza no bairro de Santa Cruz, uma das possibilidades de ser a última estação para pessoas que pegam o trem da "Supervia" na "Central do Brasil" (RJ) e um dos bairros que mais sofrem com a "sensação" de guerra civil que a cidade do Rio de Janeiro sofre.

As encenações do coletivo acontecem em três eixos temáticos principais: o modo e suporte artístico, a adaptabilidade dos clássicos e a inclusão das memórias, afetividades e pertencimentos dos moradores em material estético (principalmente em dramaturgia e encenação).

O texto Oh! Menino teve como metodologia a captação de lembranças e vivências de Mateus (um menino da "comunidade" João XXIII) pelo diretor e dramaturgo Sandro D 'França ${ }^{11}$ (também morador da João XXIII). Fato este verificado por mim através de registros como entrevistas, acompanhamentos a ensaios, presença em espetáculos registrados na minha dissertação: "A narrativa como dispositivo: a interferência da palavra na disputa da existência em certos territórios do Rio de Janeiro - Rio de Janeiro: UFRJ, 2015".

No final do processo, gerou-se uma peça que tinha como mote a apresentação no palco das histórias que só um menino da periferia poderia contar. Mas este mote mais esconde do que mostra. Não existe na peça uma propriedade desta periferia imaginada. Outro ponto é que as "lembranças" provêm de um jogo de Mateus criança (representado pelo próprio Mateus) com a imersão do Mateus Adulto (representado por Luiz Sallazar). Este Mateus adulto na realidade é uma versão do próprio Mateus, só que fracassada. Esta versão não conseguiu realizar seus sonhos e desejos, por isso a necessidade da volta à infância (a infância, aliás, é para muitas pessoas a terra dos sonhos). A cena inicial dialoga com Alice no País das Maravilhas, de Lewis Carroll (1832-1898), na busca pelo coelho branco, no entanto, para o dramaturgo na descrição da sua peça é a perseguição do Mateus Velho ao Mateus Novo "como um dia de cão. Mas um cão bravo mesmo". Logo, o que se verá adiante é que as pseudolembranças são, na realidade, as projeções dos desejos do coletivo e a vontade de pertencer e se catalogar como potência estética. Os diversos personagens da peça foram interpretados por dez atores oriundos ou residentes da comunidade. Em relação ao texto são dignas de nota para que possam ser pensadas como:

- A prosódia dos personagens. A Barbie, por exemplo, tem uma fala em que ela diz: "Ih, mais o colega só fala isso", colocando em cheque quem é o emissor da Barbie

\footnotetext{
${ }^{11}$ Sandro D’França é ator, diretor e dramaturgista oriundo de projetos sociais e artísticos na região de Santa Cruz. Fundador e integrante do Coletivo Última Estação.
} 
- o nosso imaginário sempre nos remete à norma culta -, mas quem tem o brinquedo é que cria as suas falas. Embora a indústria possa criar um conceito de beleza para a Barbie Americana-Europeia, o jogo da manipulação e apropriação se dá pelo emissor. Para uma menina da "periferia", a Barbie fala do jeito mencionado, até porque é ela mesma a propositora da enunciação deste personagem;

- A cena em que Matheus jovem retorna à cena para ver TV interfere e é interferido pelos temas abordados, em uma espécie de apropriação do conteúdo da televisão. O programa Jornal a que ele assiste, por exemplo, retrata a "economia" feita no cofrinho ou a briga de Matheus com o irmão pelo uso do computador. Ou, quando ao ver a novela, existe a possibilidade de misturar os personagens da mesma com personagens de outros programas, como vilões e mocinhas de novelas com índios de programas de bang-bang - numa espécie de imaginação criativa autoral.

Por fim, é interessante concluir como as relações presentes na vida do dramaturgo se transfiguram e misturam com a tentativa de narrativa de memória de uma criança. Assim recursos de hibridação com uma obra literária (Alice) e a vida cotidiana se misturam a fim de criar uma dramaturgia sobre o desejo de produção de arte para grupos de teatro de certos territórios não tradicionalmente contemplados (o cenário teatral carioca é prioritariamente realizado na Zona Sul e centro da cidade, tanto em patrocínios, cursos de formação regular bem como em equipamentos culturais).

Em relação a esta não contemplação, é interessante notar a distribuição das apresentações feitas pelo coletivo. Na Zona Oeste do Rio não existe a cultura de peças que fiquem em temporadas - até pela dificuldade de se encontrar equipamentos culturais nestas áreas ${ }^{12}$. Assim, tendo estreado em abril de 2011 o grupo realizou sua "temporada" em mais de 10 espaços diferentes que foram de um teatro propriamente dito, passando por um centro cultural e um centro social e chegando a apresentação final em uma rua da comunidade onde alguns membros do coletivo residiam (significando em espaços já convencionais e ressignificando em espaços não convencionais).

Estes procedimentos adotados são para mim os grandes vetores destes agenciamentos. Agenciamentos que não se fazem pela simples falação, mas sim pela apropriação de bens e sistemas. Ressignificando e recanalizando-os. Aliás, os melhores agenciamentos são aqueles que percebem o desejo, e descolam do mero plano e vão para o campo efetivo da ação (mesmo que seja através da palavra).

Estes podem até se valer dos sistemas mercadológicos para inverterem os processos de dessubjetivação.

Assim, a riqueza está em perceber que o desejo pode ter até a possibilidade de se "linkar" com ferramentas tradicionais de agenciamentos ou produtos comuns do capitalismo, como foi o caso das estratégias de José Junior com seus "Nikes" e "Adidas" importados (implícitos na epígrafe deste ensaio). Ou no vetor artístico como montar um Becket em Saravejo. Ou ainda a criação de dramaturgias híbridas para valorizar as histórias, dialogar com o cânone e manifestar os conflitos dos sonhos contra os imperativos sociais do mundo. No fim, são as tentativas de ir além da regulação

\footnotetext{
${ }^{12}$ Uma olhada rápida em qualquer guia de programação teatral (seja em revistas como OFF, Cena) ou programação de Jornal como o Globo, ou ainda nos respectivos sites da secretaria de Cultura do Estado (ou da Cidade do Rio de Janeiro) que embora a maior parte da população se concentre na zona oeste da cidade a proporção de equipamentos culturais nestes territórios é mínimo.
} 
ordinária e opressora dos dispositivos. Pois, se o poder e o controle são adaptáveis e apropriadores, as mutações e hibridizações da sociedade, da população, da cultura e da natureza estão sempre vazando, recriando suas manifestações de política na vida.

\section{Referências}

ANDERSON, Benedict R. Comunidades imaginadas: reflexões sobre a origem e a difusão do nacionalismo. Trad. Denise Bottman. São Paulo: Companhia das Letras, 2008.

BAUMAN, Zygmunt. A vida fragmentada - ensaios sobre a moral pós-moderna. Trad. Miguel Serras Pereira. Lisboa: Relógio D'Água, 2007.

BAUMAN, Zygmunt. Comunidade: a busca por segurança no mundo atual. Rio de Janeiro: Jorge Zahar, 2003.

BHABHA, H. O local da cultura. Belo Horizonte: Ed. UFMG, 2001.

BOURDIEU, Pierre. A economia das trocas simbólicas. Introdução, organização e seleção Sergio Miceli. São Paulo: Perspectiva, 2013.

BOURDIEU, Pierre. Pierre Bourdieu entrevistado por Maria Andréa de Loyola. Rio de Janeiro: Ed. UERJ, 2002.

CANCLINI, Néstor Garcia. Culturas híbridas: estratégias para entrar e sair da modernidade. 3. ed. Trad. Ana Regina Lessa e Heloísa Pezza Cintrão. São Paulo: Edusp, 2000.

CANCLINI, Néstor Garcia. Diferentes, desiguais e desconectados: mapas da interculturalidade. Trad. Luiz Sérgio Henrique. Rio de Janeiro: Editora da UFRJ, 2005.

COCCO, Giuseppe. Mundo Braz: o devir mundo do Brasil e o dever Brasil do Mundo. São Paulo: Ed. Record, 2009.

COUTINHO, Eduardo (Org.). Fronteiras imaginadas. Rio de Janeiro: Aeroplano, 2001.

DELEUZE, Gilles. O que é um dispositivo. Disponível em http://vsites.unb.br/fe/tef/ filoesco/foucault/art14.pdf. Acesso em: 15 maio 2011.

HALL, STUART. A identidade cultural na pós-modernidade. Rio de Janeiro: DP\&A, 1998.

JAVOSKI, Rafaella. AfroReggae, 20 anos de reinvenção diária. Rio de Janeiro: O Globo, 2013. In: https://oglobo.globo.com/rio/afroreggae-20-anos-de-reinvencao-diaria-7406871. Acesso em 01 nov. 2014. 
SANTOS, Eduardo de Almeida. A narrativa como dispositivo: a interferência da palavra na disputa da existência em certos territórios do Rio de Janeiro - Rio de Janeiro: UFRJ, 2015

SONTAG, Susan. Questão de Ênfase - Ensaios. Companhia das letras 2004.

SONTAG, Susan, Susan. Contra a Interpretação. Porto Alegre: LPM, 1987.

Recebido em: 29/05/2017

Aprovado em: 26/02/2018 